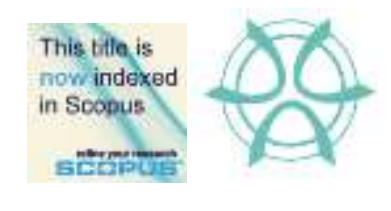

\title{
TREE CROWN MAPPING BASED ON UNMANNED AERIAL VEHICLE (UAV) TOWARDS A GREEN-SUSTAINABLE RESIDENTIAL
}

\section{Suzanah Abdullah ${ }^{1}$, Mohd Fadzil Abdul Rashid ${ }^{2}$, Khairul Nizam Tahar ${ }^{3} \&$ Muhammad Ariffin Osoman ${ }^{4}$}

\author{
${ }^{1,2}$ Department of Built Environment Studies \& Technology, Faculty of \\ Architecture, Planning and Surveying \\ UNIVERSITI TEKNOLOGI MARA, PERAK BRANCH, MALAYSIA \\ ${ }^{3}$ Faculty of Architecture, Planning and Surveying \\ UNIVERSITI TEKNOLOGI MARA, SHAH ALAM, MALAYSIA \\ ${ }^{4}$ Geoinfo Services Sdn Bhd. \\ KUALA LUMPUR, MALAYSIA
}

\begin{abstract}
Tree crown plays a crucial role in creating urban characters and spatial arrangements of living environment towards a green-sustainable city. It provides the fundamental needs for human's living quality and health conditions such as improving water quality, preserving energy, minimising greenhouse gasses, and beautification and comfortable purposes. Therefore, there is a need for urban planners to recognise its importance and plan for it wisely. This paper attempts to demonstrate a mapping tree crowns for a case of the residential neighbourhood using Unmanned Aerial Vehicle (UAV) based GIS technologies. Four main stages involved in a mapping tree crown process namely: flight planning, data acquisition, data processing and analyses and results. As a result, this paper able to show the capabilities of the technologies in measuring and mapping tree crowns for the residential neighbourhood. Moreover, it provides urban planners with informative scenario of the tree planting and clarifies its importance for future planning and benefits - in creating and promoting a green-sustainable and healthy living environment.
\end{abstract}

Keywords: Unmanned Aerial Vehicle, tree crown, urban planning, sustainable residential

\footnotetext{
${ }^{1}$ Senior Lecturer at Universiti Teknologi MARA Perak Branch. Emai: suzan156@uitm.edu.my
} 
Suzanah Abdullah, Mohd Fadzil Abdul Rashid, Khairul Nizam Tahar, \& Muhammad Ariffin Osoman

Tree Crown Mapping based on Unmanned Aerial Vehicle (UAV) Towards a Green-Sustainable Residential

\section{INTRODUCTION}

Tree crown or tree canopy plays an important role for people and all life on the earth surface. Many cities are becoming increasingly populous, bringing more impermeable lands and less spaces for vegetation-growing. Consequently, the dense urban areas require ecosystem of trees to maintain their sustainability in terms of minimising the climate change (global warming), good environment footprints and viable economic growth (Kanniah et al., 2016; Kamarul Zaman et al., 2017). As mentioned by Nowak \& Greenfield, (2012), the tree canopy becomes an important element in cities or towns for physical and socio-economic and the human health in that area . According to Turner, (2019) the right amount of tree canopy will reduce the summer temperature by 10 degrees Fahrenheit during the day. This is because, trees in and around the city provide various benefits for the city and human health, such as improving a better environment and the visual character of the place (Wallace, 2021) and also make society more alive (Turner-Skoff \& Cavender, 2019). Well-maintained tree offers a critical role for the cities to well functions. It includes increase the quality of living environment for their inhabitants, and as one of the most cost-effective strategies to reduce the effects of urbanisation such as hot islands, excessive use of electricity for heating and cooling buildings and daily pressure (Bravo-Bello et al., 2020).

Tree crown also contributes significantly to environmental sustainability, economic viability and more importantly, urban settlements liveability (Kanniah \& Siong, 2017). The trees have a symbolic and sentimental attribute for natural environment since they are expected to purify and beautify the urban areas. Trees are also required for absorption of the carbon produced from population growth and the number of vehicles used. Moreover, the trees nurtured many valuable things in our lives such as providing shade, food resources as well as generating social and economic benefits (Hasan et al., 2018). Therefore, the trees need to be preserved and thus it requires a proper plan in making more trees in urban living systems especially in dense inhabitant's areas. In other words, innovative planning and urban management on the trees will enable the existence of the structure and nature of a city (Jim et al., 2018). In micro dimension impacts, previous studies have demonstrated that the presence of tree crowns can improve the human physical health, increase attention and test scores of children, shift in the value of property of neighbourhood, reduce heating and cooling demands and decrease storm water runoff (Turner-Skoff \& Cavender, 2019; Matasci et al., 2018; Lesher et al., 2014).

Moreover, it is intended to raise the consciousness of the positive effects and their benefits to the people. Human and environmental factors are inter-related in which urban planners should pursuit the information on them to improve the living environment of the residential neighbourhood. One of the crucial or important things is to have a better understanding on cultivation of trees 
PLANNING MALAYSIA

Journal of the Malaysia Institute of Planners (2021)

canopy (Lowry et al., 2012). Usually, the tree canopy information is generated through the interpretation of aerial photograph or images like LiDAR, Airborne Laser Scanning (ALS), satellite and field inventories. These methods, unfortunately, consume extra time, very expensive and require a trained person especially in data collection and image processing stages. Nowadays, the availability of unmanned aerial vehicle (UAV) technology allows urban planners to capture a valuable information of tree canopies in less time and budget, and more importantly, can provide a very high-resolution image (Preethi Latha et al., 2019; Mohan et al., 2017; Niluka et al., 2016). This technology becomes an alternative to manned aerial vehicle due to their flexibility, unique capabilities, and the ability to reduce operating costs while increasing safety (Jenkins, 2015). UAV applications have been widely used in many areas such as vegetative health monitoring, precision farming, urban forestry, emergencies management, biological monitoring, and traffic (Ritter, 2014). With the UAV technology, it can map the urban trees effectively and monitor spatial and temporal complex urban environment changes (Timilsina et al., 2020). Therefore, this technology is becoming more important in urban planning decision making in particular in physical development process (Noor et al., 2019). Hence, the current paper attempts to demonstrate a mapping tree crown for a residential neighbourhood using the UAV based-GIS technologies to promote a green-sustainable and healthy living environment.

\section{METHODOLOGY}

\section{Study Area Description}

The study area covers a residential neighbourhood of Puncak Iskandar, Perak with an area of 61.523 hectare at latitude $4^{\circ} 22^{\prime} 26.4^{\prime \prime} \mathrm{N}$ and longitude $100^{\circ} 57^{\prime}$ 30.24 " E (Figure 1). 
Suzanah Abdullah, Mohd Fadzil Abdul Rashid, Khairul Nizam Tahar, \& Muhammad Ariffin Osoman

Tree Crown Mapping based on Unmanned Aerial Vehicle (UAV) Towards a Green-Sustainable Residential

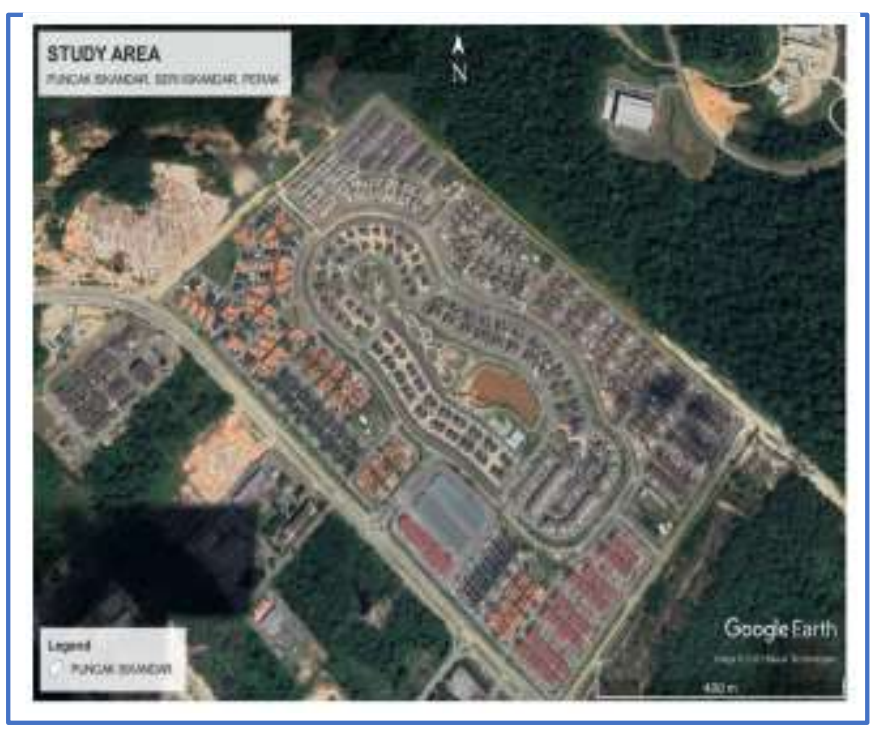

Figure 1: The case study of Puncak Iskandar residential neighbourhood, Seri

Iskandar, Perak

Source: (Keyhole, 2018)

Puncak Iskandar is one of the new residential area was developed in 2012 (or nearly 10 years in duration) in Seri Iskandar township. The development has taken multiple phases comprising multiple living houses types - detached, semi-detached, terrace with a modern houses design and compounded neighbourhood facilities and services to attract buyers to come in. This provides an appropriate case study to evaluate the trees species and its characteristic towards a green-sustainable residential. In this study, UAV DJI Phantom 4 pro was used for data acquisition in Puncak Iskandar residential area. The Agisoft Metashape Professional software is used to process all the images derived from UAV, while the ArcGIS software is used to determine the existing tree covers and mapping the entire area of the case study.

\section{Tree Crown Mapping Process}

The process of tree crown mapping involved four main stages which include preparation and flight planning, data acquisition, data processing, results, and analyses of the results. The discussion starts with elaboration of flight planning stage that consists of flight path and mission. It is followed by a discussion on data acquisition stage that comprises of image acquisition of the study area. The next is the data processing stage of being executed to generate the orthophoto. It is the crucial part to obtain the results. The final stage, that is, analyses stage. 
PLANNING MALAYSIA

Journal of the Malaysia Institute of Planners (2021)

\section{Flight planning}

Flight planning was setup with an application software named ground station pro (DJI GS Pro) for the UAV operations - a fully autonomous flight. The application automatically calculates the study area location and flight paths based on image overlap and pre-determined flying altitude. The flying height was set up to 150 $\mathrm{m}$ above ground level and the value of the ground sample distance (GSD) of 3.15 $\mathrm{cm} /$ pixel is automated calculated based on camera pixel size and flying height. Both the sides and front overlaps were set at 70 percent to provide more essentials for precise photogrammetric processing. The UAV operations is conducted using DJI Ground Station Pro (GS pro), an iPad application to implement the automated flight mission. All the parameters such as waypoints, flying altitude and overlapping images were configured using GS pro before flight mission (see Figure 2).

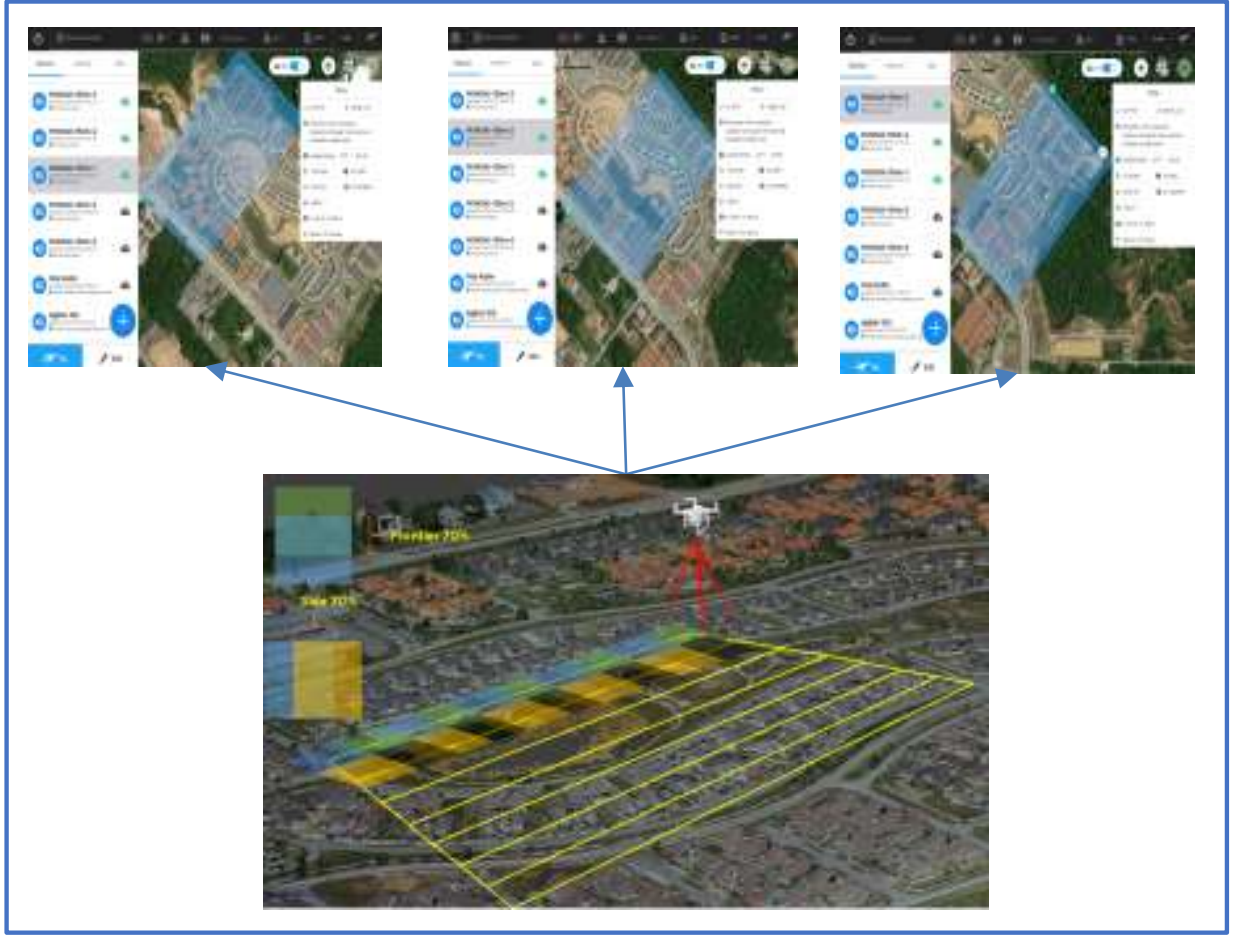

Figure 2: The flight planning process before the flight mission

\section{Data acquisition}

As continue to the above-mentioned process, the data acquisition was conducted using UAV DJI Phantom 4 pro to capture the photogrammetric images of the case study of Puncak Iskandar residential neighbourhood. In this study, the 
Suzanah Abdullah, Mohd Fadzil Abdul Rashid, Khairul Nizam Tahar, \& Muhammad Ariffin Osoman

Tree Crown Mapping based on Unmanned Aerial Vehicle (UAV) Towards a Green-Sustainable Residential

separate mission of data acquisition was conducted for covering the whole area of Puncak Iskandar. It is because, the limitation of flying time which can only capture for 20 minutes per mission. As the results, a total of 990 images were captured covering the entire study area with a stereo camera view at $150 \mathrm{~m}$ flying altitude. As aforementioned, the flight was monitored using DJI Go software, which interconnected with the UAV through a wireless remote controller. Figure 3 shows the several images captured in multiple locations at $150 \mathrm{~m}$ flying altitude.

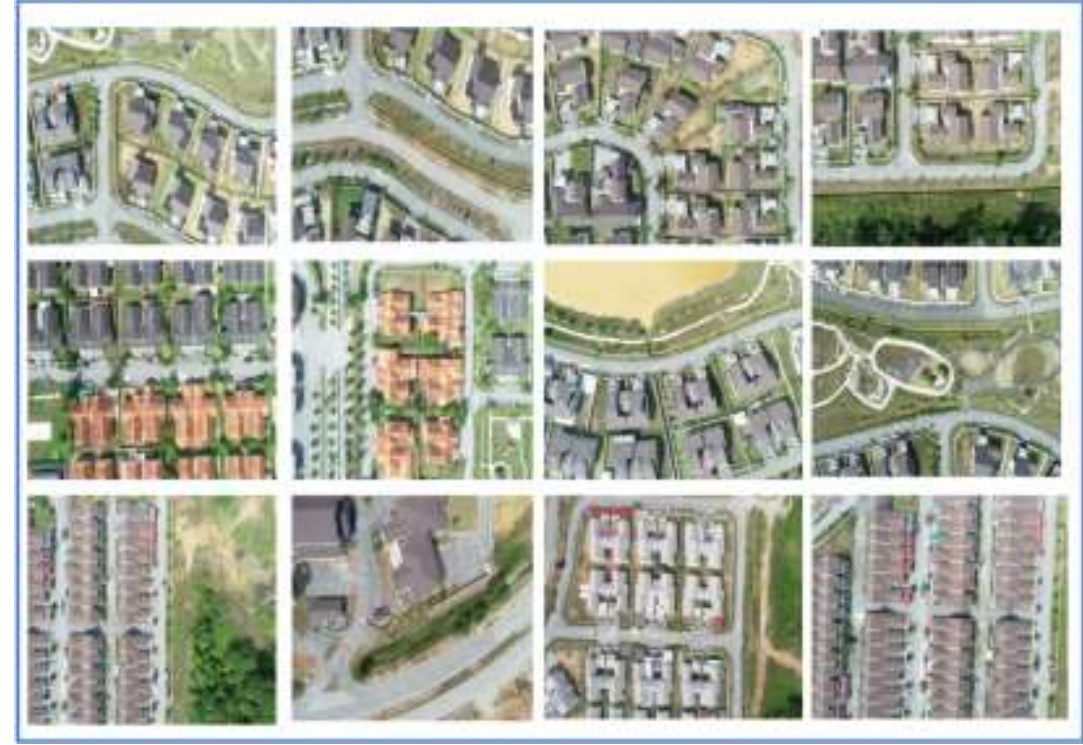

Figure 3. Example images derived from the UAV at $150 \mathrm{~m}$ flying altitude

\section{Data processing}

At this stage, all the captured images were processed using Agisoft Metashape Professional software to produce the UAV RGB images for generating DSM and orthophoto images. The process includes photo alignment based on the computer vision concept to ensure all the photo overlays are connected and fit all together. Another process is the build dense cloud to calculate the depth information for each camera. It was followed by generating the $3 \mathrm{D}$ model as a mesh building to create DSM, DTM and orthophoto images.

Figure 4 shows the entire images processing using the Agisoft Metashape Professional software to produce the orthophoto as the final expected product. The orthophoto image (Figure 4) was then processed for identifying the tree planting sites using UAV-based GIS in the ArcGIS software environment system. 


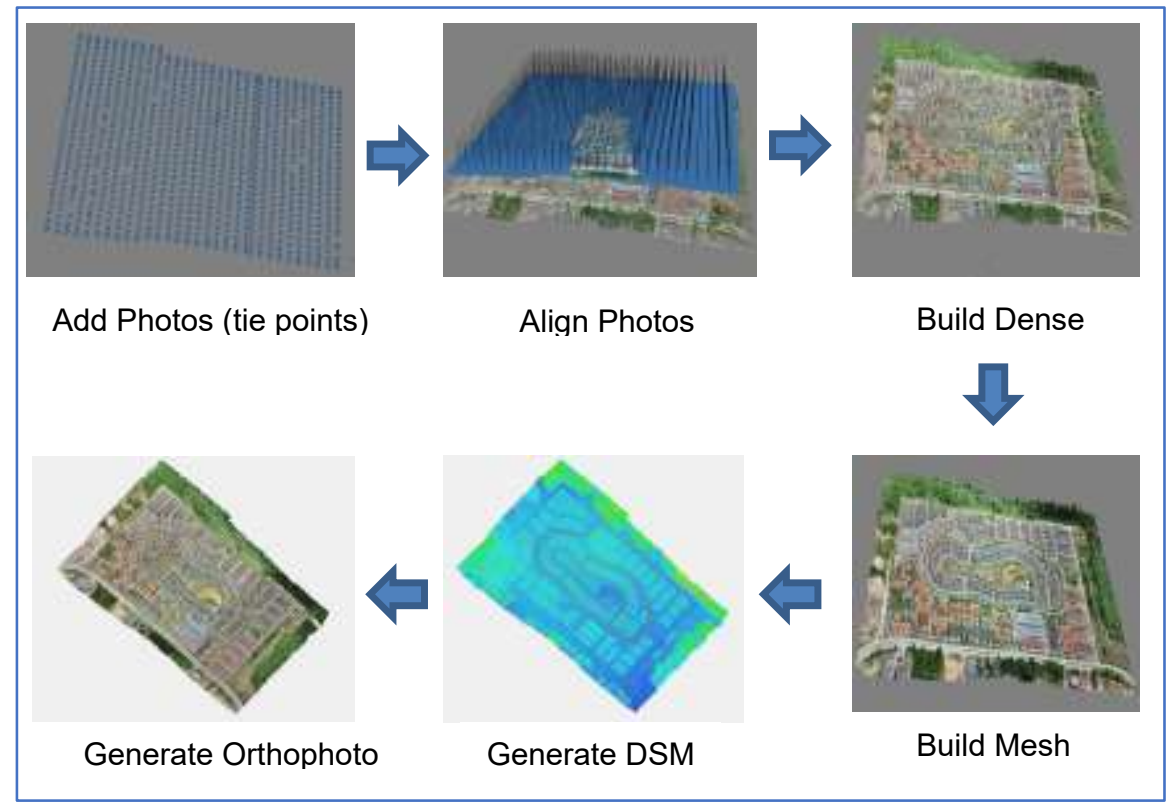

Figure 4: The process of images processing

\section{Data analysis}

Figure 5 shows the tree crown overlay (mapping) results in two forms of data produced in the ArcGIS namely: DSM data, and orthophoto data.

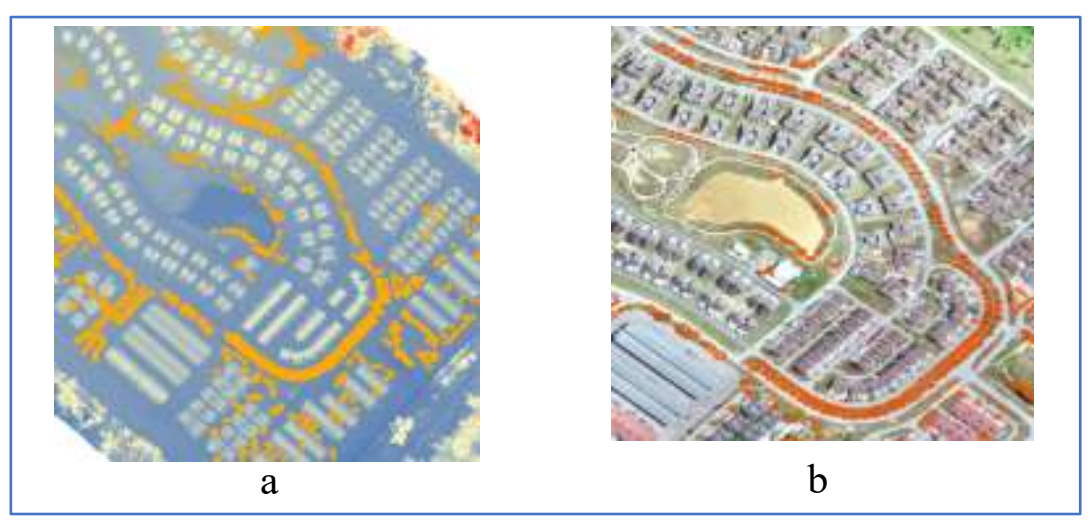

Figure 5: Tree crown overlay with (a) DSM data (b) Orthophoto data

As refers to Figure 5, the planted trees (in orange colour) are manually digitized based on orthophoto data and it is a clear indication that only a small per cent of the lands are covered with planted trees. The total area of planted and 
Suzanah Abdullah, Mohd Fadzil Abdul Rashid, Khairul Nizam Tahar, \& Muhammad Ariffin Osoman

Tree Crown Mapping based on Unmanned Aerial Vehicle (UAV) Towards a Green-Sustainable Residential

non-planted were calculated to map the needs of tree canopy at Puncak Iskandar area. More detail discussion on the tree crown mapping results and the percentages will be presented in the next section.

\section{RESULTS AND DISCUSSIONS}

As discussed earlier in the introduction, the tree canopy planting is embedded with an essential desired outcome. At this extent, many cities in the world experiencing negative effects associated due to not maintaining an adequate level of tree canopy coverages.

Figure 6 indicates the existing tree crown coverage, where the orange colour represents the tree crown planted, while the hatch colour shows the nonplanted. It proven that many areas are still left and not covered with the tree canopy to make it greener, comfort and healthy areas to absorb carbon and other pollutant agents.

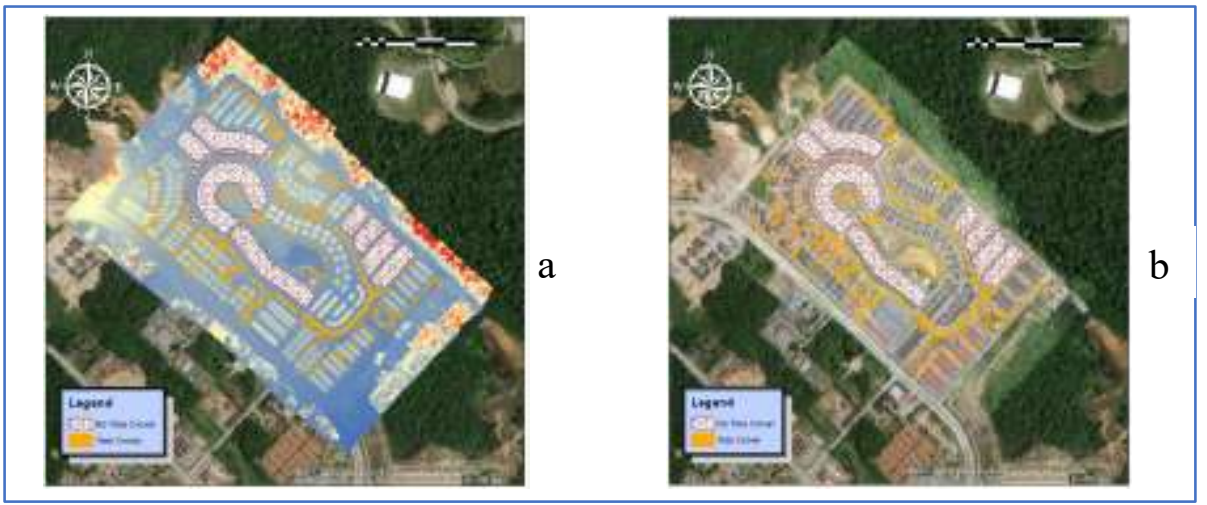

Figure 6: The location of tree crown planted and non-planted (a) without Orthophoto (b) with Orthophoto

The tree canopy mapping at Puncak Iskandar area was determined based on the results shown in Figure 6. It was found that the canopy cover estimated derived from the UAV imagery indicates that the entire residential areas fall below recommend canopy cover levels. Hence, it indicates lacking in the social and environmental awareness that needs to be prioritized in particular by tree planting engaging collaborative groups from community stakeholders. The preservation and plantation of the tree canopy should remain as ongoing development continues to occur. In addition to that, the existing tree crowns along the streets mostly the sparse crown which is not fulfilled the distance as imposed by the National Landscape Department, Malaysia Negara (2020), where a single tree crown should cover for every two units of houses and with a suitable distance range of $30 \mathrm{ft}$. to $40 \mathrm{ft}$. The guideline is aimed partly to prevent any future problem and causing harm to people who lived in the areas. 


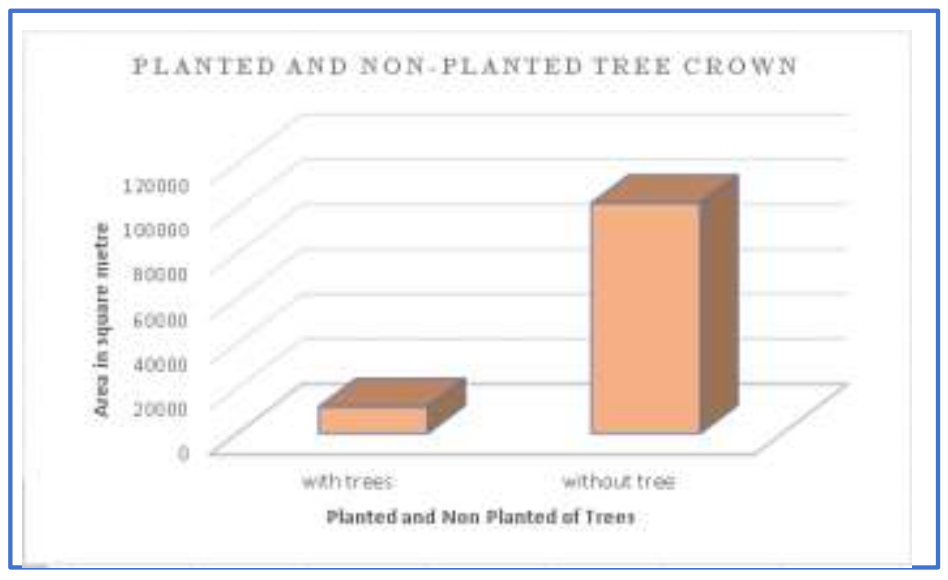

Figure 7. Percentage of the areas planted with trees (tree crown) compared to nonplanted

In the percentage (see Figure 7), the tree crowns for the planted and nonplanted were calculated as of $11,926.769 \mathrm{~m}^{2}$ and $10,2566.473 \mathrm{~m}^{2}$, respectively. The figures show an obvious difference between the planted crown and non-planted crown, and it would impact the residents' living environment. The amount of oxygen produced by a tree depends on several factors including tree species, age, health and environment of the tree. Mature leafy trees produce as much oxygen in one season as 10 people breathe in a year. On average, one tree produces nearly 260 pounds of oxygen each year (Helmenstine, 2019). Each hectare that consists of $100 \%$ canopy, balances the oxygen consumption from 19 people per year (Lucas, 2019). According to the existing situations, trees canopy was not good enough to accommodate the population inhabitant as of 59 hectares in the case study.

\section{CONCLUSIONS}

This paper showed the results of the tree canopy using UAV-based GIS technologies. The processes and results are significant to show the capabilities of the technology tools in mapping tree crowns for residential neighbourhood trees planning. By identifying the main structural trees throughout Puncak Iskandar, it can better understand on their role in providing a better ecosystem for the urban population. The tree crown assessment establishes a spatial data that can be used in conjunction with other infrastructure layers derived from UAV images. It is also used to identify the potential planting sites to increase canopy coverage especially in urban area. The detection of tree canopy can be determined by using the UAV technology as well as can identify the suitable areas for other trees planting. 
Suzanah Abdullah, Mohd Fadzil Abdul Rashid, Khairul Nizam Tahar, \& Muhammad Ariffin Osoman

Tree Crown Mapping based on Unmanned Aerial Vehicle (UAV) Towards a Green-Sustainable Residential

Moreover, it provides urban planners or stakeholders with an informative scenario of the trees planting and managing the case study. As a working action by means, there is a need for further intervention in trees planning and planting in a neighbourhood area. Besides that, urban residents need to recognize and voiced up the importance of trees as a crucial component of a neighbourhood living environment and thus reducing the conflict between the people and the environment. Moreover, the selection of trees to make it compatible with the planting location is very important and these understandings should be applied among associated organisations. With this, makes urban and neighbourhood areas a better and safer to live, play and work. In the end, for many applications in urban planning decision-making, the capabilities of UAV and GIS technologies are opened and thus will illustrate in other works.

\section{REFERENCES}

Bravo-Bello, J. C., Martinez-Trinidad, T., Valdez-Lazalde, J. R., Romero-Sanchez, M. E., \& Martinez-Trinidad, S. (2020). Analyzing potential tree-planting sites and tree coverage in Mexico City using Satellite Imagery. Forests, 11(4), 1-12. https://doi.org/10.3390/F11040423

Hasan, Ramly; Othman, N. I. F. (2018). Developing Malaysia roadside tree species selection model in urban areas. Planning Malaysia Journal of The Malaysian Institute of Planners, 16(3), 248-260.

Helmenstine, A. M. (2019). How Much Oxygen Does One Tree Produce. BBC Science Focus, 2-3. Retrieved from https://www.thoughtco.com/how-much-oxygen-doesone-tree-produce-606785

Jenkins, N. A. L. (2015). An Application of Aerial Drones in Zoning and Urban Land Use Planning in Canada. University of Guelph.

Jim, C. Y., Konijnendijk van den Bosch, C., \& Chen, W. Y. (2018). Acute challenges and solutions for urban forestry in compact and densifying cities. Journal of Urban $\begin{array}{lll}\text { Planning and Development, } & \text { 144(3), }\end{array}$ https://doi.org/10.1061/(asce)up.1943-5444.0000466

Kamarul Zaman, N. A. F., Kanniah, K. D., \& Kaskaoutis, D. G. (2017). Estimating Particulate Matter using Satellite Based Aerosol Optical Depth and Meteorological Variables in Malaysia. Atmospheric Research, 193, 142-162. https://doi.org/10.1016/j.atmosres.2017.04.019

Kanniah, K. D., Kaskaoutis, D. G., San Lim, H., Latif, M. T., Kamarul Zaman, N. A. F., \& Liew, J. (2016). Overview of atmospheric aerosol studies in Malaysia: known and unknown. Atmospheric Research, 182, 302-318. https://doi.org/10.1016/j.atmosres.2016.08.002

Kanniah, K. D., \& Siong, H. C. (2017). Urban forest cover change and sustainability of Malaysian cities. Chemical Engineering Transactions, 56, 673-678. https://doi.org/10.3303/CET1756113

Keyhole. (2018). Puncak Iskandar, Bandar Seri Iskandar, Perak.pdf.

Lesher, A., Rosenbloom, J., \& Duerksen, C. (2014). Tree canopy cover. Retrieved August 24, 2020, from https://sustainablecitycode.org/about/

Lowry, J. H., Baker, M. E., \& Ramsey, D. (2012). Determinants of urban tree canopy in 
residential neighborhoods: household characteristics, urban form, and the geophysical landscape. Urban Ecosystems, 15(1), 247-266. https://doi.org/10.1007/s11252-011-0185-4

Lucas, D. (2019). Rural Landscape Development Guideline. New Zealand Agricultural Science (Vol. 17)

Matasci, G., Coops, N. C., Williams, D. A. R., \& Page, N. (2018). Mapping tree canopies in urban environments using Airborne Laser Scanning (ALS): A Vancouver case study. Forest Ecosystems, 5(1). https://doi.org/10.1186/s40663-018-0146-y

Mohan, M., Silva, C. A., Klauberg, C., Jat, P., Catts, G., Cardil, A., ... Dia, M. (2017). Individual tree detection from Unmanned Aerial Vehicle (UAV) derived canopy height model in an open canopy mixed conifer forest. Forests, 8(9), 1-17. https://doi.org/10.3390/f8090340

Negara, J. L. (2020). Garis Panduan Kemudahan Rekreasi dan Landskap.

Niluka, M., U I, M., Premasiri, H. M. ., N, L. D., Madawalagama, S. 1, \& Samarakoon, L. (2016). Developing methodology to map tree canopy in urban areas from low cost commercials UAVs. In 37th Asian Conference of Remote Sensing (Vol. Colombo, p. 7). Columbo Retrieved from https://www.researchgate.net/publication/309349770_Developing_Methodology To_Map_Tree_Canopy_In_Urban_Areas_from_Low_Cost_Commercial_UAVS

Noor, N. M., Abdullah, A. A. A., Abdullah, A., Ibrahim, I., \& Sabeek, S. (2019). 3D City Modeling using Multirotor Drone for city heritage conservation. Planning Malaysia Journal of The Malaysian Institute of Planners, 17(1), 338-349. https://doi.org/10.21837/pmjournal.v17.i9.610

Nowak, D. J., \& Greenfield, E. J. (2012). Tree and impervious cover in the United States. Landscape and Urban Planning, 107(1), 21-30. https://doi.org/10.1016/j.landurbplan.2012.04.005

Preethi Latha, T., Naga Sundari, K., Cherukuri, S., \& Prasad, M. V. V. S. V. (2019). Remote Sensing UAV/Drone technology as a tool for urban development measures in APCRDA. International Archives of the Photogrammetry, Remote Sensing and Spatial Information Sciences - ISPRS Archives, 42(2/W13), 525-529. https://doi.org/10.5194/isprs-archives-XLII-2-W13-525-2019

Ritter, B. (2014). Use of Unmanned Aerial Vehicle (UAV) for Urban Tree Inventories. MSC Thesis.

Timilsina, S., Aryal, J., \& Kirkpatrick, J. B. (2020). Mapping urban tree cover changes using Object-based Convolution Neural Network (OB-CNN). Remote Sensing, 12(18). https://doi.org/10.3390/RS12183017

Turner-Skoff, J. B., \& Cavender, N. (2019). The benefits of trees for livable and sustainable communities. Plants, People, Planet, 1(4), 323-335. https://doi.org/10.1002/ppp3.39

Turner, M. (2019). Trees are crucial tothe future of our cities. ScienceDaily, pp. 2019 2022. Retrieved from https://www.sciencedaily.com/releases/2019/03/190325173305.htm

Wallace, R. \& T. (2021). Tree canopy preservation. Connect Our Future, 1-6.

Received: $17^{\text {th }}$ May 2021. Accepted: $9^{\text {th }}$ July 2021 